can be no chemical affinity between them and the basic cellulose hydrates. It is also pretty clear that the cellulose hydrates have not the power to combine directly to the extent of being "sized" with either free rosin acids or aluminum hydroxide, but that when combined as a resinate of aluminum, the size having been beaten into the fibers and precipitated, there is a sufficient breaking-up of the resinate and combination both of the rosin acid and alumina, relatively acid, to combine with the cellulose to effectually size it.

Finally, as a corollary to this proposition, we must conclude that papers whose stuff has been treated with hard waters or to which calcium sulphate has been added as a filler cannot be sized as effectually, for the reason that they precipitate the size before the addition of alum is made, leaving no work as a precipitant for the alum to do. This is found to be true in practice.

Mechanicsville, N. $\mathbf{Y}$.

\title{
ON THE PRESENCE OF COTTON-SEED OIL IN LARDS FROM HOGS FED UPON COTTON-SEED MEAL.
}

By A. D. EMMETT AND H. S. GRINDLEY. Received December 2I, Ig04.

Having had occasion to make for the Department of Animal Husbandry, of the Experiment Station of the University of Illinois, quantitative determinations of cotton-seed oil in lards rendered from the fat of hogs fed largely upon cotton-seed meal, a more detailed study of the samples was undertaken in order to add, if possible, some information as to whether cotton-seed oil actually existed in the body fat of the animals.

That many of the vegetable oils enter into the make-up of the body fat in some manner or other, there can be but little doubt. Lebedeff, ${ }^{1}$ and Henriques and Hansen ${ }^{2}$ in feeding linseed cake, Monk ${ }^{3}$ in feeding rape oil and the fatty acids from mutton tallow, Lebedeff ${ }^{4}$ and Rosenfelt ${ }^{5}$ in feeding mutton fat; and Shutt ${ }^{8}$ in feeding maize, have shown that the resulting fat differs mate-

1 Zischr. physiol. Chem, , 6, 149.

2 Thier. Chem. Ber., 29, 68.

a Ibid., 14, 4 II.

4 Ztschr. Physiol. Chem., 6, I49.

5 Thier. Chem. Ber., $25,44$.

6 Canada: Cen. Expt. Sta. Bul1., 38. 
rially from the normal fat body in appearance and propertiesmelting-point and iodine number.

On the other hand, Radziejewsky ${ }^{1}$ with rape seed oil, Subbotin ${ }^{2}$ with soap, Lebedeff ${ }^{3}$ with tributrine, Henriques and Hansen ${ }^{4}$ with linseed oil on cows, Bömer, ${ }^{5}$ Harrington and Adriance, ${ }^{6}$ Virchow, ${ }^{7}$ Van Engelen, ${ }^{8}$ Solstein, ${ }^{9}$ Langfürth, ${ }^{10}$ and Fulmer ${ }^{11}$ with cotton-seed meal, were unable to obtain affirmative results in their feeding experiments, although in almost every instance there were some abnormal changes detected in the fat. In the cases of cotton-seed meal some of the investigators found, by the Halphen and Bechi colorimetric tests, as high as 15 to 30 per cent. of the oil.

Thus, admitting that the presence of vegetable oils influences the fat of animals to some extent, the question arises as to how these oils exist in the body fat. Are they assimilated unchanged through the lacteals and thus find their way into the circulatory system, being carried on to the fat cells? Are they first broken up into simpler bodies and then absorbed by the lacteals, or are they subjected to the intricate processes of metabolism-saponified by the bile, etc.-and converted into animal fat?

The fact that Monk, in feeding rape oil to dogs, not only found the olein content of the body fat much above the normal, but that he was able to separate eruic acid, a characteristic ingredient, tends to show that in one case, at least, the vegetable oil was evidently absorbed unchanged. On the other hand, since Henriques and Hansen found, in their work on the feeding of linseed oil to pigs and dogs, that the same ration may affect the fat of one animal and not that of another; and since Lebedeff in feeding the same animal on different fats-linseed oil and tributrine-was able to detect a change in the former case but none in the latter, it tends to indicate that the nature of the assimilation of the rations varies under certain conditions-with the animal and kind of animal and with the fat and kind of fat.

1 Virchow's Archiv, 56, 2II; 43, 268 .

2 Ztschr. f. Biol., 6, 73 .

s Ztschr. Physial. Chem., 6, 149.

4 Thier. Chem. Ber, 29, 68.

i Ztschr. Unt. Nahr. u. Genus., 1899, 2.

- Texas Expt. Sta. Bull., 29.

Ztschr. Unt. Nahr. u. Genus. (1899), 8, 46-48.

Chem. Centrbi, $1899,2$.

- Zeit. offentl. Chem., 8, I40.

10 Ztschr. angew. Chem., 14,685 .

11 This Journal, 24, 1148; 26, 837. 
To answer this question of assimilation in the case of cottonseed meal-fed hogs, there seemed but one way as suggested by Hehner $^{1}$ in 1880 , when European markets were being flooded with adulterated American lards, namely, to actually establish the presence of a vegetable oil. At that time, the solution resolved itself, in the case of cotton-seed oil, into the following statement: If a lard gave the Bechi-Maumene test together with a high iodine value and a low melting-point, it should be condemned. But in cases of doubt, Salkowski's method for the separation of vegetable cholesterin should be applied. Later, many other colorimetric tests were submitted, chief among them being the nitric acid and the Halphen tests. Of the former, Lewkowitsch ${ }^{3}$ stated, previous to the appearance of the latter, that he preferred it to all others. Halphen's test, however, has come into prominence and is considered to-day to be the most convenient and reliable method, both from the qualitative and the quantitative standpoint, for estimating cotton-seed oil, and by many it has been given the preference to the once official Bechi test.

In dealing with lards from hogs fed upon cotton-seed meal, the factors are to some extent different from those in the case of rendered lards mixed with cotton-seed oil. The analytical numbers-iodine absorption value, and melting-point-are not trustworthy, although indicative. Bömer ${ }^{4}$ has shown that the variations in the iodine number make this test impracticable. Albert ${ }^{5}$ and likewise Henriques and Hansen ${ }^{b}$ have found that the composition of the fat from different parts of the same animal is subject to great differences in melting-point and iodine number. In the case of Albert, these variations were greater, on the average, than could be ascribed to any feeding ration. Hence, in this short study, we have directed our attention chiefly to other tests for determining qualitatively the presence of a vegetable oil.

One of the supposed essential differences between animal and vegetable oils is in their monatomic alcohols called cholesterins. The former, animal cholesterin, crystallizes from hot alcohol in rhombic plates, and the latter, vegetable cholesterin and desig-

1 Analyst, 13, I65.

2 Ztschr. anal. Chem., 26, 557.

3 "Oils, Fats and Waxes," Benedickt and Lewkowitsch.

* Ztschr. Unter. Nahr. u. Genus, , 1898, 532.

5 Landw. Jahrb., 28, 96r.

- Bied. Centr. Blatt. Agr. Chem., 30, 182. 
nated by Hesse: as phytosterin, crystallizes in needles arranged in stars, fans or bundles. According to Bömer, ${ }^{2}$ in a mixture of the two cholesterins, the phytosterin either takes on the form of elongated plates which may or may not have angles at the ends, or if it is in much the greater proportion, of needles which lie upon the rhombic plates of the animal cholesterin. Van Kettel $^{3}$ states that another distinguishing feature of some vegetable oils, and especially cotton-seed oil, is that they give the pentosan reaction. In this connection Rudzinski ${ }^{4}$ has recently shown that the pentosans occur in company with the carbohydrates in the plant cells and are closely connected with cellulose, a prominent constituent of cotton-seed meal. Slovtzov ${ }^{5}$ also states that a part at least of pentosans is absorbed by the animal body. In I 89 I Welman ${ }^{6}$ proposed his phosphomolybdic test for vegetable oils, suggesting that the reaction might be due to glucosides. In $190 \mathrm{I}^{7}$ he defended the attacks upon his test and added that the final blue coloration which would also result if amines were present, was of little value, as the characteristic feature was the green color produced when the nitric acid was added. Seiler and Verda ${ }^{8}$ have lately stated that Welman's reaction, though not a positive test, gives good indications of the presence of vegetable oils in admixtures of animal fats or mineral oils.

Again, as suggested above, Bömer worked upon the separation or detection of a vegetable oil in lards from cotton-seed meal-fed hogs. His conclusions were that inasmuch as he could not obtain crystals of phytosterin, the vegetable oil was not retained in the animal fat. He also stated that since a trace of the fatty acids lowers the melting-point of the crystals, the differences in their form should be relied upon rather than that of the melting-point. Virchow, who also worked upon this question, obtained results agreeing with Bömer as to the separation of phytosterin and the presence of a vegetable oil in the body fat. Solstein in his work was likewise unsuccessful in isolating the vegetable cholesterin and also in obtaining positive results with the Welman reaction. $\mathrm{He}$

+ Ann. Chem. (Liebig), 192, 175.

2 Mitt. d. Kgi. Techn. Versuch., $18,255$.

3 Monat. Scientifique, 1900.

* Ztschr. physiol. Chem., 40, 317.

¿Ztschr. Unter. d. Nahr. u. Genuss., Igo4, p. 2.

- Pharm. Ztg., 36, 79 \%,

7 Ztsehr.f. offentl. Chem., 6, 143; 4, 852

8 Chem, Ztg., 27. 
stated that a lard, although it might give the Halphen test, should not be condemned unless it gave Welman's reaction and crystals of phytosterin.

It is noteworthy, at this point, that where the Halphen, Bechi, and nitric acid colorimetric tests have been applied to lards from cotton-seed meal-fed hogs, these reactions have been obtained almost without fail. The majority of investigators agree that each of these characteristic reactions for cotton-seed oil is dependent upon a specific constituent in the oil for its ultimate color. If this is the case, then the animal fat has apparently assimilated these three bodies in their unaltered condition, either through the medium of the unchanged cotton-seed oil or its simpler decomposition products, for, should they have been subjected to the regular processes of metabolism, it is difficult to conceive that they could have been transmitted to the fat cells without one of them having lost its characteristic property.

In our work, samples of leaf and ham fat were obtained from each of four hogs which had been fed largely upon cotton-seed meal. The fats were rendered in the laboratory at a low temperature, not exceeding $120^{\circ} \mathrm{C}$. A sample of leaf fat, known to be free from cotton-seed oil, was also rendered at the same time and under the same conditions. Quantitative determinations of cotton-seed oil were then made on each of the eight samples of lard by the Halphen and Bechi-Hehner tests. The amount of cotton-seed oil was found to range from 5 to 5 per cent. The Bechi-Hehner method gave somewhat higher results throughout.

The first four samples of the above lards were then taken for the more detailed study as to the presence of the vegetable oil.

In applying the nitric acid tests to these lards, the characteristic brown color appeared at once and was very pronounced. A blank test upon the pure lard gave no color, even after standing twenty-four hours.

As suggested by Van Kettel, Tollen's ${ }^{1}$ phloroglucinol hydrochloride reaction for pentosans was tried. With each of the samples a distinct reddish pink ring was noticeable at the juncture of the two layers. A parallel determination upon the pure sample gave no such results, showing that pentosans were present in the lards in question.

Welman's phosphomolybdic test was carefully tried. The ${ }_{1}$ Jour.f Landw., 40, 13. 
characteristic green and blue colorations were obtained repeatedly when applied to the samples in question, but in no case could they be produced with the pure lard.

Having been successful in these characteristic tests, attention was then directed to the separation of the vegetable cholesterin, phytosterin, believing, with Salkowski, Hehner, Bömer, Solstien and others, that should this unsaponifiable substance be found, the evidence would be still stronger in favor of the presence of a vegetable oil in the lards.

Three attempts were made to separate the phytosterin. First, Von Raumer's ${ }^{1}$ method was found to yield a substance which agreed fairly well with the description of phytosterin, but the quantity obtained was so small that no positive results could be procured. Forster and Riechelman's ${ }^{2}$ method was then applied. The yield was somewhat larger than in the previous case and the same characteristic features concerning the crystalline formation were noticeable. In this instance, a parallel determination was nade upon a sample of cotton-seed oil. There was a similarity in their crystalline structure, but we were still dissatisfied with the results. In a somewhat recent article by Ritter, ${ }^{3}$ he has shown that his method for the separation of cholesterin from fats will give a larger yield than any of the others. We were led to try this procedure in our case. Briefly stated, it is as follows: Fifty grams of the fat are heated in a porcelain dish upon a waterbath with roo cc. of alcohol. This solution is saponified by the addition of a hot mixture of 8 grams of sodium hydroxide and $I 60 \mathrm{cc}$. of strons alcohol. It is then evaporated and 75 grans of sodium chloride are added and the whole is dissolved in hot water. The solution is brought to dryness with continued stirring and the residue pulverized, and left over sulphuric acid for some time. The dried mass is then extracted with ether for at least nine hours, using a Soxhlet apparatus. The extract is freed from ether at a low temperature and the residue of cholesterin is finally taken up with hot alcohol and allowed to cool slowly, when crystals will separate.

Two hundred grams of the lard in question and 50 grams of pure cotton-seed oil were carefully treated as just stated. As a result, we obtained a much larger yield than in either of the other

\footnotetext{
1 J. Soc. Chem, Indi, 1898, p. 774 .

2 Analist, r897, p. 13 r.

3tschr. physiol. Chem, 34, 451
} 
two methods, although the amount obtained in this case was still small. The crystals from the evaporation of the ether were needles. After treatment with hot alcohol and allowing the crystallization to continue slowly, needles again separated. In the case of the cotton-seed oil, they were arranged in stars, and in the case of the lard, in leaf-like forms. Upon recrystallization, the stars retained their same general shape, but the leaf-like forms changed into bundles of needles. These bundles crossed each other at different angles, forming clusters. A second recrystallization of these bundles gave crystals of a distinct fan shape with a star of needles as a base and having the fascicular portion built up from this nucleus. By recrystallizing these again, they passed into the previous form-bundles of needles. Salkowski's chloroformsulphuric acid test for cholesterin was applied to this small quantity of crystals. The test proved the presence of a cholesterin and the crystalline form indicated that it was probably phytosterin.

However, as a further confirmation of the presence of phytosterin, Bömer ascertains the melting-point of the acetic esters of these crystals. He states ${ }^{1}$ that this method is a very sensitive one for detecting the kind of cholesterin. If the melting-point of the crystals is $I I 6^{\circ} \mathrm{C}$. or higher, it shows phytosterin to be present. This method has been used by Tolruan ${ }^{2}$ in attempting to identify phytosterin in lard from cotton-seed fed hogs, in which he obtained negative results. Juckenack and Pasternack ${ }^{3}$ agree with Bömer in regard to the acetate test for phytosterol, but they do not make any statement as to its delicacy. On the other hand, Siegfeld ${ }^{4}$ states that while the test is accurate, it is not sensitive in the cases of the fats with which they workedmargarin and palmitin-to less than Io per cent. Bömer claims that cotton-seed and sesame oils, which are frequently present to considerable extent in margarin, can be detected by this test when present to the extent of only $I$ to 2 per cent. It is thus apparent that there is still a difference of opinion as to the delicacy of this test. In our work, as a result of repeated experiments, we always obtained crystals which closely resembled those of phytosterin but as yet we have not been able to prove conclusively the presence of this substance by the melting-point of its acetate.

\footnotetext{
1 Ztschr. Unter. Nahr. u. Genus., 4, IgoI; 5, 1902.

2 Science, 1904,763 .

3 Ztschr. Unter. Nahr. u. Genus., 7, 1904.

4 Ibid., 7, I904.
} 
This brief study, which was originally undertaken in order to confirm the Halphen and Bechi tests for cotton-seed oil in lards from hogs fed upon cotton-seed meal, has been found to present so many subjects of interest upon which as yet very little has been published that we are now making still further investigations upon the problems involved.

\section{CONCLUSIONS.}

These several samples of lard rendered from the fat of cottonseed meal-fed hogs, were found to give the following tests for vegetable oils: (I) Welman's reaction; (II) Tollen's pentosan reaction; (III) Salkowski's cholesterin reaction; and (IV) crystals resembling phytosterin. The samples also gave the following tests for cotton-seed oil: (I) the Bechi; (II) the nitric acid; and (III) the Halphen reactions. From this it is evident that two statements can be made, first that the lards contain a vegetable oil, and second, if we agree with the most recent authorities, they contain three distinct constituents of cotton-seed oil. Hence, it seems safe to say that a part at least, of the oil existing in cotton-seed meal, is absorbed, in the case of hogs fed upon this ration, by the animal body and transmitted in its unaltered condition to the fat cells.

[CONTRIBUTION FROM THE LABORATORY OF THE BUREAU OF INTERNAL, REVENUE, U. S. TREASURY DEPARTMENT.]

\section{THE DETECTION OF PALM OIL WHEN USED AS A COL- ORING MATERIAL IN OILS AND FATS.}

By C. A. Crampton and F, D. Simons.

Received January 9, Ig05.

THE high natural color of palm oil, together with the difficulty of detecting its presence when mixed with other oils and fats in small proportion has led to its use as a means of imparting a color to oleomargarine. In most of the cases that have occurred under the Federal law, the palm oil has been incorporated in the product by the use of cotton-seed oil, to which 2 to 5 per cent. of palm oil had been added. Two oils of this character, sold in the trade as "butter oils," gave the following figures: 